\title{
Cientificamente favelados: uma visão crítica do conhecimento a partir da epistemografia'
}

\author{
Scientifically marginalized: a critical view of \\ knowledge from epistemology
}

Antonio GARCÍA GUTIÉRREZ²

RES U M O3

Análise do conhecimento, e de sua organização, a partir da Epistemografia interativa, opondo-a à Epistemologia. Esta última, tradicionalmente vinculada ao conhecimento ordenado e elitista, termina por ignorar grande parte do conhecimento socialmente produzido, confinando-o às favelas do conhecimento. Ao propor, em seu lugar, a Epistemografia interativa, destaca-se, em primeiro lugar, a necessidade de incorporar ao conhecimento e à sua organização as questões éticas, culturais e políticas. Nesse sentido, o objetivo da Epistemografia é estar presente nos ambientes de conhecimento propositalmente excluídos dos processos contemporâneos de inscrição e fluxo, de modo a possibilitar sua incorporação às redes digitais em que transitam os conhecimentos dominantes. Para isso, propõe a criação de ferramentas para desclassificaro conhecimento, tanto o que já está classificado, como o que está por ser classificado. Tal desclassificação supõe a reabilitação da contradição, como recurso pós-epistemológico, e a substituição da lógica dominante por uma lógica paraconsistente. A Epistemografia intervêm, portanto, para acolher o conhecimento excluído, devolvendo-lhe a legitimidade negada pelos processos convencionais de reconhecimento e ordenação.

Palavras-chave: epistemografia interativa, epistemologia, organização do conhecimento, comunidades não-epistemológicas.

\section{A B STRACT}

Analysis of the knowledge, and its organization, using interactive epistemography as opposed to epistemology. The latter, which has been traditionally tied with methodical and elitist knowledge, actually ignores great part of the socially produced knowledge, confining it to marginalized knowledge. When considering instead, the interactive epistemography, the need to incorporate to knowledge and to its organization ethical, cultural questions and politics is firstly emphasized. Consequently the objective of the epistemography is to be present in knowledge environments which are purposedly excluded from contemporaneous processes of registration and flow, in order to enable its incorporation to digital networks, through which, dominant knowledge pass. Thus, it considers the creation of tools to declassify knowledge, whether already classified, or being classified. Such declassification assumes a reinstating of contradiction, as an after-epistemologic resource, and the substitution of dominant logic for paraconsistent logic. Therefore, epistemography intervenes in order to welcome excluded knowledge, returning the legitimacy which has been denied by conventional processes of recognition and ordinance.

Key words: interactive epistemography, epistemology, organization of knowledge non-epistemologic communities.

\footnotetext{
- Texto de conferência proferida no Seminário Unesco Chemins de la pensée. Rio de Janeiro, 1-2 junho 2006. Traduzido por Nemézio Amaral Filho (Doutor em Comunicação e Cultura pela UFRJ). Revisão técnica de Nair Yumiko Kobashi (Professora doutora da ECA-USP). Resumo elaborado por Marivalde Moacir Francelin (aluno de doutorado do Programa de Pós-graduação em Ciência da Informação - ECA/USP).

2 Professor titular, Departamento de Periodismo I, Facultad de Comunicación, Universidad de Sevilla. Rua Américo Vespucio, s/n, 41092 , Sevilha, Espanha.E-mail:<algarcia@us.es>.

Recebido e aceito para publicação em 28/6/2006.
} 


\section{N T R O D Ç Ã O}

Debater a dicotomia Ciências/Ciências Humanas implica refletir sobre a teoria que naturalizou essa disjunção: a Epistemologia ${ }^{4}$. Neste debate, gostaria de me situar na perspectiva da epistemologia prática, segundo expressão de J.C Gardin (GARDIN, 1987), ou da epistemografia interativa, como prefiro denominá-la, incorporando-lhe uma dimensão sociocultural, ética e política, em suma, crítico-pós-moderna. Já afirmava George Steiner (STEINER, 1999) que, antes que homo sapiens, somos homo quaerens (perguntadores). Da mesma forma, "Perguntando, caminhamos", dizem os zapatistas. Por isso, em todo debate sobre o saber deveríamos retomar a pergunta política inicial: conhecimento para quê? Conhecimento para quem?

Quem teria legitimidade para estabelecer distinções entre os conhecimentos ou levantar fronteiras entre eles? Alguma academia ocidental? A Social Science Index ou o último índice de impacto de revistas? A Bolsa? A demagogia neoepistemológica, que devolve a razão exclusivamente ao senso comum? Seria "a rua", como categoria que agora se ergue como árbitro da racionalidade? Ou, em suma, seriam os desfavorecidos, esse pensamento-outro do Sul espoliado, como indica Walter Mignolo, os únicos que poderiam articular um pensamento decente?

Do ponto de vista epistemográfico, todas as instâncias têm direito à razão e ao direito de transmiti-la em igualdade de condições. De outro modo, estaríamos ante uma nova e sutil estratégia de dogmatização e de totemização: para que uma categoria seja válida, deve ela ser sempre única e todo-poderosa. Inclusive "a terceira via", como categoria, poderia sublimar-se até sua corrupção: a terceira via já não seria o ponto de fuga ou de ruptura, mas a conversão perversa das dicotomias em tricotomias.

A epistemografia(GARCÍAGUTIÉRREZ, 1998, 2002, 2004, 2005) é uma configuração transdisciplinar que tem como objeto a organização horizontal

4 Para Rorty, um episódio próprio da cultura ocidental. gerados pelos indivíduos. exomemoria ${ }^{5}$. Conseqüentemente, em sua aplicação cotidiana, lida com conceitos bem conhecidos e mitificados pela Epistemologia moderna, tais como categoria, classificação, ordem (de ordenação e mandato), método, conhecimento, formalização, metacognição ou representação, entre tantos outros. Mas, em sua vocação democrática e reabilitadora dos vícios humanos, excomungados pelo tribunal neocartesiano, a epistemografia, opondo-se aos idealismos e aos absolutismos - também ao absolutismo relativista -, se permite questionar a Epistemologia a partir de pegadas despercebidas e colaterais: em seus bueiros e esgotos, em seus despojos e contradições. Nesses lugares, que deve freqüentar em seu trabalho cotidiano, o epistemógrafo observaria com um sentido indicial (Peirce/Ginzburg) e tafonômico ${ }^{6}$.

$\mathrm{Na}$ elaboração de cartografias do saber e mapas conceituais, na classificação dos conhecimentos e na organização das memórias, evidenciam-se muitos inconfessáveis epistemológicos. No seguimento diacrônico de teorias e certezas brotam pontos escuros, seguramente imputáveis a processos heurísticos complexos e inexplicáveis que irrompem nos intestinos da criação, a retóricas e contradições ocultas e condenadas pela Epistemologia, a dissimuladas estratégias psicagógicas e erísticas, que causariam vergonha a um pesquisador de elite.

No apogeu da certeza reside o germe de sua decadência, como sabe todo cientista e como todo epistemógrafo desvela em seu trabalho cotidiano. A história da ciência seria, também, a história do desprezo do subalterno. Mas, também, uma história repleta de valiosas irrelevâncias, de felizes inconsistências, de oportunos esquecimentos e, especialmente, de imprevisíveis contradições que criam, com uma força motriz sempre negada, a poderosa máquina do conhecimento e todas as suas tecnopróteses.

A partir da modesta posição da epistemografia, tal como no submundo - aos olhos dos senhores - do filme brasileiro Domésticas, de Fernando Meirelles, dispomos de uma privilegiada plataforma de observação dos vice-reinados virtuais e das neocomendas digitais que se acumulam, sem cessar, em torno da indústria e dos tribunais do conhe-

${ }^{5} \mathrm{~A}$ exomemória abarca todas as inscrições humanas, em suporte físico ou digital, sejam eles conhecimentos ou lembranças.

- A tafonomia é uma disciplina que estuda os hábitos e estruturas sociais em depósitos de lixo ou em outros depósitos de restos orgânicos 
cimento. Tal posição permite-nos divisar um novo Tratado de Tordesilhas, que alguns impulsionam como linha divisória das Ciências e como discriminação entre modos de cognição, sistema amparado por esse monarca em decadência que é a Epistemologia.

Creio que no Brasil, como em muitos outros países, existe uma dupla percepção: a de um Brasil minoritário, imaginário e unificador, inventado e vivido pelas elites financeiras, petroleiras e latifundiárias e a de um Brasil profundo e diverso, com uma maioria de gente sem-terra e de habitantes de favelas. Em Ciências, bem valeria como uma metáfora: a Epistemologia representaria esse mundo ideal do conhecimento competitivo e bem sucedido e, a epistemografia, se ocuparia do conhecimento despercebido. Assim, a partir de sua posição sensível, a epistemografia adentra tanto nos privilegiados vice-reinados das áreas científicas como na imensidão das favelas do saber, mas com interesses reais e conhecimento digno, que sobrevivem em seu entorno. Eis aqui um objetivo essencial de nossos estudos.

A epistemografia tem suas raízes em disciplinas positivistas como a Biblioteconomia ou a Museologia, das quais luta por se libertar ${ }^{7}$. São ciências que adotam paradigmas, divisões, hábitos e nomenclaturas do pensamento moderno, que pretendem representar em arquivos, catálogos, mapas e outros artefatos de inscrição e classificação de conhecimentos, com os quais mantêm um regime de dependência, determinando todas as práticas cognitivas da vida cotidiana ocidental. Mais ainda: mediante a maquinaria de transmissão colonial, e atualmente neocolonial, transladam-se os esquemas e cosmovisões da ciência metropolitana a outros territórios e mentalidades que bem poderiam sobreviver distantes deles.

Em relação à perspectiva pós-colonial, acompanho a crítica essencial que lhe fazem Michael Hardt e Toni Negri (HARDT; NEGRI, 2002). Segundo os autores de Império, o investigador pós-colonial estaria obcecado pelas antigas categorias coloniais e imperialistas, categorias relegadas pelo novo regime imperial mundial. Mas, sobre o colonialismo, deve-se fazer um esclarecimento óbvio: nossas sociedades foram e são tão invasoras como invadidas, do mesmo modo que nossos corpos o são pela educação, a viagem, a diáspora e os vírus. Por essa razão, ao integrar à epistemografia a necessária economia política do conhecimento - sim, podemos livrar-nos da obsessão pelas pegadas do dominador - não poderíamos propor um utópico mundo descolonizado, mas trabalhar por uma redistribuição da presença e força de todos os conhecimentos e culturas na rede digital, em igualdade de condições.

A expansão do digital e da tecnocultura obriga, sem dúvida, a um exercício de pluralismo ético, que consiste em criar ferramentas que não apenas auxiliem na organização dos "conhecimentos dominantes", mas, especialmente, que promovam a resistência dos conhecimentos considerados subalternos. Esses conhecimentos, culturas e memórias estão ameaçados por projetos globalizantes de substituição e, conseqüentemente, não lhes resta outra saída senão apropriarem-se do digital como única possibilidade de auto desenvolvimento (devolver a diversidade com as tecnologias unificantes, dirá James Clifford). Incorporar nas redes digitais os conhecimentos excluídos dos fluxos em que transitam os conhecimentos dominantes: essa seria, resumindo, uma função tecnopolítica da epistemografia interativa ${ }^{8}$.

Ao comprometer-se com a dignidade, com a democracia e, de um ponto de vista pragmático, considerar que não há ciência transcendental, mas usos científicos, a epistemografia coloca suas próprias ferramentas a serviço da participação no próprio conhecimento, indo além do mero conceito mercantilista de acesso. Nesse sentido, a epistemografia explora e fornece ferramentas independentes da Epistemologia, autorevelando sua presença e evitando envolver-se nas práticas de auto-organização que propõe: categorias polissêmicas e porosas, indagações intersticiais (in-betweenness), hierarquizações autodesmontáveis, conceitos abertos e dinâmicos,

\footnotetext{
7 Para se libertar da orientação positivista, o epistemógrafo deve ter formação permanente em gnoseolgia, neurociência, sociologia do conhecimento, teoria e economia política, estudos interculturais e poscoloniais ou teoria feminista, entre outros.

${ }^{8} \mathrm{Na}$ sociedade pós-nacional, o conhecimento dominante não seria elaborado somente nas antigas metrópoles, mas também nas "ilhas tecnocientíficas" da Coréia do Sul, Índia ou China (a periferia central). Do mesmo modo, o conhecimento excluído tampouco seria produzido apenas nesses países, mas também no próprio coração industrial de Manhattan, Londres ou Berlin (o centro periférico).
} 
relações interconceituais polivalentes e inclusive contraditórias, pluralismo lógico e racionalidades heterogêneas e mediadas culturalmente, favorecimento de hibridações, busca do dissenso e da diversidade, antes que de consenso e unificação.

A epistemografía propõe operações de organização horizontal do saber e da memoria registrada, formando-se como a corporificação algológica (de "algos": dolor) de um conhecimento e memória gerados com toda dignidade pelos despercebidos do planeta. Em suma, constituiria a dimensão material desse espírito intransigente que caracteriza a Epistemologia, pois, como disse Santos (1989), ela dita, para as ciências, leis incapazes de serem aplicadas a elas próprias.

A epistemografia tem aprendido, em suas práticas com o conhecimento, a conviver e aceitar os componentes mais negados de sua natureza, como o pluralismo lógico, a contradição ou a má fé argumentativa. Comentarei brevemente, em seguida, os elementos constitutivos da construção do conhecimento e do conhecimento científico.

\section{Opressões lógicas}

Ao longo da história da Lógica, e da Epistemologia, têm sido impostos dogmas e repressões múltiplos e redundantes em relação aos modos humanos de se autoconhecer e de perceber o mundo do qual faz parte. Uma das violações sistemáticas reiterada em cada tratado, em cada teoria, em cada afirmação inquestionável e cotidiana - corresponde à esfera do conhecimento: sendo seres de natureza contraditória - salvos pela sagaz estratégia proporcionada pelo pragmatismo de cada situação -, sendo seres pré-programadamente desesperados ante um mundo incompreensível, vemo-nos forçados a aceitar o governo de uma lógica única e universal que nega a condição natural da diversidade humana. Uma das pré-condições da diversidade é a contradição. A unidade lógica é, por excelência, inimiga do diverso.

A lógica é uma estrutura culturalmente determinada. Ou são loucos todos os homens idosos, de uma etnia da Guiné Papua, que, para morrer com dignidade, querem ser enterrados vivos sob os detritos de seu gado? Se a lógica ocidental Ihes arrebatar essa possibilidade, levando-os a um hospital australiano, talvez essa lógica seja indigna e humilhante. Perderam o juízo as centenas de milhares de pessoas dispostas ao suicídio, no Oriente Médio, ou elas respondem a outras lógicas? E os mártires cristãos que se atiravam aos leões? Sem dúvida, as lógicas são determinadas pelas crenças. Mais ainda, as lógicas são as crenças.

Eu creio ${ }^{9}$ firmemente na contradição como recurso epistemológico: estarei, então, abandonando a lógica de nossa racionalidade? As ciências, as crenças, as identidades, as memórias e, até o passado ou os sonhos, são construídos a partir de categorias obrigatoriamente respeitosas com o princípio da não-contradição, como mostra Newton da Costa (COSTA, 1997), em sua lógica paraconsistente. Essa atividade noológica é urdida em torno de conceitos unívocos, blindados por hierarquias férreas, sujeitas a matrizes cognitivas e culturais ancestrais.

O peso da História e a densidade da Tradição e da Mitologia colocam o centro de gravidade da cognição, e suas disputas, na coerência entre premissas e predicados. A coerência se configuraria como o exorcismo que afugenta a contradição e a desordem em todo pensamento. Alguém tão pouco afeito às convenções, como o próprio Marx, foi inevitavelmente, como se sabe, filho de sua época positivista e determinista: ele mesmo se dedicou a denunciar dialeticamente as contradições do capitalismo como elementos que acelerariam seu fracasso. Obviamente, Marx não se deu conta do aleatório e caprichoso itinerário das decisões humanas, e outros fluxos transversais, formadores da complexidade do real, e pensou que, necessariamente, a contradição levaria o sistema capitalista ao seu desaparecimento. Mas, a julgar pelo que temos visto no mundo contemporâneo, o pensador alemão foi limitado em seu vaticínio: não seria a contradição, mas o êxito inexplicável do sistema de exploração e lucro que poderia levar à extinção, para além do próprio capitalismo, de toda a espécie humana. Que interesse ou eficácia teria, nessa suposição, a obsessão com a denúncia de um regime contraditório?

\footnotetext{
•E, curiosamente, em espanhol dizer "eu creio" (yo creo) implica, simultâneamente, crere criar.
} 
À luz da reflexão anterior, não parece possível invocar a contradição como um argumento permanentemente eficaz para derrubar um postulado, uma teoria ou um sistema, tendo-se em conta que tais construções, se dispõem de cláusulas sérias de autodefesa, são capazes de sobreviver e crescer sobre as contradições. Poderiam ser negados eticamente embora não exista ética sem cultura -, mas não logicamente. A blindagem, então, passaria por um exercício permanente de acoplamento cultural, de fechamento de fileiras, de sobrevivência em um corpo invasor ou de convivência com o corpo invadido. $E$ no extremo, a contradição seria vista como necessária, como o desafio ou a peça incerta que, só com este estatuto, se encaixa e permite fazer encaixes em um conjunto explicativo.

Todas as culturas e matrizes cognitivas têm gerado precauções especializando-se em técnicas de blindagem discursiva que erradicam a auto-contradição, ao mesmo tempo em que a evidenciam no outro. Omitir a contradição no seio de estruturas ideológicas e míticas tem sido um sutil setor no qual se esmeraram de maneira eficaz colonizadores, evangelizadores e expansionistas, talvez suficientemente conscientes, ou simplesmente atemorizados, pelas forças obscuras que subjazem em suas mentes também submissas e oprimidas. Como rizomas subterrâneos que escavam e negam secreta, mas vigorosamente, o outro lado da superfície, as contradições e contra-sentimentos acabavam em rebelião, no ressentimento denunciado por Nietszche, na loucura ou no suicídio. E, inclusive, nas situações que mostram a desconstrução: não é possível uma ordenação positiva que omita o seu contrário, isto é, não é possível ordenar sem a cooperação da desordem. Portanto, não seria factível classificar eficiente nem afetuosamente o mundo sem liberar as forças da desclassificação.

Conhecemos a partir de categorias supostamente consistentes, ou seja, filtradas pelo principio da não contradição. Pois bem, muito pouco sabemos sobre a microfísica, os intercâmbios e as emanações entre essas categorias. De fato, as categorias cognitivas não seriam finalizadas senão nas falácias previstas em tipologias teóricas ou filosóficas. No universo imanente, o sujeito traz nas mãos, mais do que categorias fechadas, estratégias categoriais renegociadas no calor das interações. Desse modo, em situações extremas, poderíamos negar princípios invioláveis sem surpreender-nos e, imediatamente depois, restaurar o sistema anterior ou agarrarmonos a uma tábua de salvação que nos chega como parte de um inesperado itinerário. A contradição fundamenta nossa própria existência física. Senão, como, ao final das contas, explicar que, graças ao envelhecimento celular, rejuvenescemos momentaneamente para envelhecer progressivamente: viver enquanto nos autoincineramos?

O contraditório afeta também às categorias éticas, das quais o sujeito pode se sentir refém, em algum momento. Como já advertira William James, os princípios devem ser quebrados quando se transformam em obstáculo instransponível ${ }^{10}$. Neste cenário, a ética estaria violentando seus fiéis e convertendo-os, eventualmente, em escravos. Prisioneiros da ética: seria esta uma ética possível?

A própria batalha que a lógica mantém - e perde - com o objetivo de erradicar a retórica da produção de conhecimento científico, isto é, do seio de seu campo privilegiado de atuação, já foi suficientemente evidenciado por Santos (1989). Todo conhecimento científico é essencialmente retórico. $\mathrm{E}$ Muniz Sodré, em sua sutil exploração espeleológica dos confins do afeto, vai além, colocando a emoção no centro de todo raciocínio e de toda ação. De fato, a própria lógica convencional elaboraria tipologias dicotômicas nas quais situa a emoção ou o irracional como adversária da racionalidade, produzindo assim um cisma e a falta de possibilidade de cooperação entre essas potencialidades igualmente geradoras e criativas do cérebro humano.

A prática cognitiva, nossa relação com o mundo, então, se estabelece sobre parâmetros que cerceiam uma substancial parte de nossas estruturas e respiradouros cognitivos naturais. A opressão do sistema, porém, não acaba terminantemente com os poderosos recursos que a evolução colocou no paleocéfalo e no neocórtex. O espírito e a resposta contraditórios fluem, sempre que necessário, para

10 A frase exata de William James é: "A vida ética mais elevada consiste em todo momento na violação das regras que passam a ser muito estreitas” (ELSTER, 1989, p.181). 
restaurar qualquer desequilíbrio inesperado ante 0 que a episteme não sabe acudir com a rapidez e o silogismo necessários. No conhecimento íntimo, as contradições, como modo de cognição, se relacionam sem pudor com as estruturas lógicas e éticas de cada época. Não obstante, não se trataria de rebelarmonos contra a positividade, em benefício de uma regressão ao império da pulsão ou da consciência pré-lingüistica; ao contrário, trata-se de autodevolvernos uma antiga herança cultural da qual a Epistemologia, seguramente sem má fé, nos tem privado, tanto à civilização ocidental quanto aos territórios que ela continua neocolonizando.

\section{Conhecimento localizado}

A mitologia ocidental tem sustentado a crença predominante na pureza ontológica do conhecimento e do valor, seja como resultado do itinerário racional ou empírico corretamente aplicado, seja em referência ao processo mesmo da cognição, sejam eles os defensores do objetivismo positivista ou da subjetividade presente em seu processo construtivo. Mas são precisamente as posições subjetivistas, como o perspectivismo crítico nietzcheano ou a sutil rebeldia de Spinoza, quando afirmava - alterando um inquestionável princípio - que não escolhemos as coisas boas; ao contrario: são boas porque as escolhemos, que introduziram uma decisiva inflexão no pensamento estabelecido.

A epistemografia deve ser orientada (e não apenas ocidentada, como afirma Norval Baitello) por um conhecimento situado, no sentido proposto por Donna Haraway. Haraway (1988) propõe partir de lugares determinados, para compensar o relativismo crescente que impede a averiguação crítica. Esse tipo de conhecimento é necessariamente monista, mas de um monismo específico, contaminado por elementos cognitivos e não cognitivos, por emoções e paixões, por mestiçagens, ambigüidades e contradições. Sua ontologia monista se nutre, paradoxalmente, da promiscuidade de todos os recursos perceptivos humanos e se reconhece passageira, precária, parcial, sempre insuficiente, vulnerável, falível, mas possível, transformadora e crítica.
Para conhecer o mundo precisamos, sem dúvida, de duas ferramentas: das categorias e de uma classificação que as organize. Mas para acompanhar mais amavelmente a complexidade do mundo, tal classificação teria de ser evolutiva ${ }^{11}$ e plural: necessitamos, então, justamente de seu contrário, da desclassificação, conceito ambíguo e complexo, de primeira ordem, que propusemos no desenvolvimento de nossa teoria.

A desclassificação é uma ferramenta central da epistemografia. Sua função consiste em instalar o pluralismo lógico no coração mesmo da classificação. Com efeito, se a perspectiva lógica permanece predominantemente linear e monológica, os resultados de sua ação poderiam ser "liberados", em virtude do ato de desclassificar. O conhecimento cientifico, numa tríplice dimensão, teria de ser desclassificado: 1) desmontando-se as nomenclaturas que somente garantem o status quo; 2) proporcionando-lhe categorias compatíveis com o pluralismo lógico e 3) no sentido metafórico - e social - da desclassificação, interalimentando-se com a consciência e o domínio públicos.

Assim, a Ciência seria uma prática mais respeitável de saber, cujo objetivo é a felicidade humana. Não seria possivel, então, uma ciência sem dignidade. E dignidade humana implica justiça social. Para a mente moderna, a ciência constitui a grande utopia (o lugar que não existe), um lugar que está a ponto de converter-se no metarrelato ocidental dominante de nossa era. Mas julgo que, pelo contrário, a ciência deve recobrar seu estatuto de humildade e encampar a marcha da justiça social à eutopia (o lugar feliz planetário).

\section{Conhecimento submerso}

A assunção de um conhecimento necessariamente localizado revela a existência de um imenso conhecimento submerso, despercebido. Esse conhecimento, não menos útil para suavizar o sofrimento humano do que um conhecimento "oficial", muitas vezes distante ou ausente, ocuparia, no mínimo, vários milhares de vezes o volume do conhecimento registrado. Em virtude de seu

" Um conceito de evolução que permita "dar passos atrás ou improdutivos" aos olhos de um neodarwinista. 
compromisso sociocultural e político, a epistemografia promove ferramentas destinadas ao resgate e reabilitação de todas as formas de cognição e seus resultados e práticas mediante sistemas de auto-narração de indivíduos e comunidades. Estes introduziriam as próprias perspectivas e cosmovisões para explicitare dar a conhecer um acervo já existente e indispensável, a rigor, para o arquivo digital mundial.

Nesse sentido, a epistemografia se separaria de toda suspeita de relativismo, pois acredita na intervenção exterior. Porém, não poderia considerar-se anti-relativista posto que propicia itinerários exclusivos - mas cooperativos - para cada estrutura lógico-semântica, estrutura inseparável de uma mediação cultural singular.

Porém, ao ocupar lugar na rede, não sofreria o conhecimento excluído um processo de expansão que provocaria a inevitável perda de alguns símbolos identitários? Para sobreviver, para serem preservados, os patrimônios culturais e cognitivos hão de adaptar-se aos novos meios ou preparar-se para a extinção. Os conhecimentos submersos devem interacoplar-se estruturalmente para poder continuar dando conta de seu legado, e aprender que a transmissão e a organização são tão importantes como o próprio conhecimento. Esse conhecimento subalterno teria o direito e o dever de ser transmitido.

O papel da epistemografia, como ferramenta estranha a tais conhecimentos, não seria menos perigoso, inicialmente, que a ação do conhecimento oficial, trasladando intencionalmente ou não, estruturas não desejáveis. Nesse aspecto, todo projeto epistemográfico haveria de ser utilizado como a provisória escada wittgensteiniana, à qual é necessário dar um pontapé uma vez subido o muro.

O caráter transdisciplinar e necessariamente dialógico da epistemografia garante um filtro de extrapolações e métodos eficazes em universos já organizados e até naqueles que ainda precisam de auto-organização. Pois o objetivo é manter os níveis máximos de conhecimento auto-construído, autônomo, emancipado, heterológico, ainda com baixo ou nenhum nível de tradução, mediante o trabalho cooperativo na rede.

\section{Má fé e epistemografia}

Dediquemos, agora, algumas palavras para reabilitar a má fé como constituinte da atividade epistemológica. Mas reclamar a má fé, obviamente, não para praticá-la, mas, ao contrário, para construir mecanismos de explicitação e denúncia nas representações do conhecimento. Por isso, a dialética da má fé por excelência, a erística, se configura como outra peça central de nossos estudos.

Platão - no O Banquete - já dizia que não poderíamos compreender um texto sem reconstruir a vida de seu criador (PLATÓN, 1997). Nesse sentido, revelam-se muitos discursos teóricos contrários à prática de seus autores, como é o caso exemplar de Schopenhauer: o pregador da filosofia do ascetismo era um sujeito submerso, digamos assim, na vida mais mundana. Como entender uma proposta, salvo na ficção, desvinculada de seu proponente? A retórica da má fé existiria, então, na construção das explicações, dos objetos e até dos fatos científicos ${ }^{12}$.

Falamos de uma má fé muito extendida na vida contemporânea: a que acompanha a ânsia de poder, em qualquer estrato social, a competitividade, - lucro. A má fé fantasiada de desconfiança. O cientista não está livre da má fé que possa ter qualquer cidadão. Se há má fé no pesquisador, esta afetaria seu processo de cognição e, inexoravelmente, se trasladará aos conhecimentos e práticas resultantes.

No ato de registro, de escrituração de categorias sinuosas, enrugadas, enganosas, se revelam as infâmias e virtudes que constituem todo saber. Sem essa massa elementar contraditória apenas estaríamos ante um novo simulacro do conhecimento. Aepistemografia, através de representações de múltiplas situações, termina por mostrar as omissões, as contradições e, inclusive, a má fé evidenciada e encurralada em alguma posição ${ }^{13}$.

12 Se, como afirmam Latour e Woolgar (1995), os fatos científicos também são construções, estes, e não apenas suas explicações, conseqüentemente, não estariam isentos da possibilidade de má fé. Por outro lado, essa "ingênua má fé" da "pirâmide da credibilidade" (Eminências, Academias, Prêmios...) é ilustrada com um exemplo por Marina (2005, p.35), que descreve como os mesmos artigos aceitos e publicados em prestigiosas revistas norte-americanas de psicologia foram rechaçados, anos mais tarde, ao serem enviados novamente, assinados por pesquisadores de universidades desconhecidas.

${ }^{13}$ Mediante um instrumental antierístico estudado em outro lugar (GARCÍA GUTIÉRREZ, 2005, 2006). 


\section{Violência da classificação. Desclassificar o mundo}

Conhecemos por meio de uma ação classificatória. O mundo, sob este prisma, não seria mais que o resultado de uma operação de ordenação urdida, em primeira instância, pela cultura e linguagem. Classificar tem, entre suas muitas acepções, uma aparência perversa e paradoxal: ocultar conhecimento. Seu contrário, a desclassificação, significaria, conseqüentemente, sua exposição. Mas se somente através da desclassificação conhecemos, como explicar, então, que conheçamos também mediante seu oposto, a classificação?

É possível ensaiar uma resposta em pleno território da contradição, como temos feito neste trabalho: desclassificar, isto é, desmontar uma estrutura de ordenação dominante - geralmente hierárquica -, implica reclassificar com parâmetros diferentes aos dessa estrutura. Como conseqüência, desclassificar suporia, no limite, classificar. Uma diferença estaria, suavizando-se então a contradição absoluta, no caráter aberto da desclassificação frente ao hermetismo da classificação.

Não negaremos categoricamente, portanto, a inevitabilidade da classificação nem os bons frutos que, em relação a algumas descobertas positivistas - apesar de seus sérios efeitos secundários -, tenha podido oferecer ao conhecimento. Obviamente, e à vista dos grandes males que as ordenações hierárquicas têm trazido à cultura e à convivência, em nossa teoria advogamos por seu contrário. Nessa concepção, a classificação seria considerada como uma operação de categorização excludente, cuja orientação última é o dogmatismo (e, por sua vez, o dogmatismo nos devolveria hierarquias à sua medida). De outro lado, deve entender-se a desclassificação como uma operação com categorias abertas, cuja tendência última é o pluralismo lógico, cultural, social ou cognitivo. Classificar, no sentido tradicional, divide e separa segundo princípios hierarquizantes e totalitários. Desclassificar, por outro lado, é introduzir uma nova ordem, classificando segundo diferentes lógicas, para agregar, reunir. Dividir pode ser, cojunturalmente, uma operação eficaz se somente se efetua para - a seguir - voltar a unir o cindido, pois a mera disjunção gera obscuri-dade, enquanto o conhecimento requer cooperação, agregação, reunião.

Devemos aprender a desclassificar o mundo e a utilizar a contradição como um instrumento eficaz para a explicação do mesmo. Na maioria dos enunciados e posições é possível forçar a contradição. Não apenas neste texto, mas em minha linha de pensamento dos últimos anos, adotei uma postura de aliança com a contradição. Desse modo, quando a racionalização convencional chega ao seu limite, recorro à lógica da contradição como recurso epistemológico de primeira ordem (por exemplo, mediante a construção de oximoros). Ao introduzir contrários nos fluxos, muito mais poderosos que os dominantes, brotam idéias e soluções, nunca definitivas, mas capazes de convulsionar os paradigmas mais consistentes.

O poder classifica colocando monumentos ${ }^{14}$ para exaltar sua memória e fossos para aturdir a inconveniência. Silenciar o mundo parece relativamente fácil. As próprias etiquetas classificadoras devem vociferar com clareza os seus âmbitos fora dos quais nada resta e, assim, produzem dobras que silenciam o que é prejudicial para o estabelecido. Porém, quanto mais aterradora a etiqueta, maior a quantidade de silêncio que pretende produzir. Ao não conseguir escapar de sua própria negação, a etiqueta foge para a frente, à luz do poder e é cegada por ela, descobrindo sua cimentação ausente.

Mas na viagem ao topo classificatório, as etiquetas ficam obcecadas com o mundo que cobrem, deixando fissuras que passam despercebidas. De fato, uma classificação de qualquer tipo é uma rede urdida para ordenar a consciência e, nessa estrutura, há tanto material positivo como negativo, unido ou separado, como se queira ver, por um limite dinâmico. A ação significativa desse limite é responsabilidade de nossas categorias.

Creio suficiente o dito - e já termino - para enunciar a violência da classificação: 0 ato de classificar não é mais do que uma prescrição, ou uma

\footnotetext{
${ }^{14}$ Os monumentos geofísicos marcam a memória em ruas e praças. A temporalidade estaria marcada por uma monumentalização baseada em comemorações e aniversários.
} 
proscrição, que deixa pouca margem à apelação. $\mathrm{O}$ conhecimento e a memória - o sujeito, em suma - não podem senão submeter sua sensibilidade - sua estesia - com o objetivo de adequar-se às etiquetas e categorias (sua anestesia). E, ao classificar, não estamos apenas ordenando um território: segundo se olhe, pode ser sua desorganização aos olhos dos outros. Descompõe-se um mundo dado para impor uma outra disposição, pois toda nova classificação comporta previamente uma desclassificação do âmbito atingido.

Classificar supõe enviar ao exílio todas as ordens possíveis, salvo as autorizadas pelo poder. $\mathrm{E}$ são, na realidade, essas ordens exiladas, que não se foram nunca, que terminam por subverter a aparente calma classificatória. No interior das categorias se farão fortes, serão cúmplices dos próprios textos maltratados e instigarão à derrubada de seus anfitriões.

A classificação, a diferença da desclassificação, revela um mundo ao preço de ocultar todos os demais. Classificamos de uma posição cujas coordenadas foram predeterminadas por uma lógica dominante. No Ocidente, o código disjuntor herdado da Árvore de Porfírio, e de outras raízes procedentes de velhos temores bíblicos, organiza nossa cosmovisão e comportamento em torno de uma lógica e de um sistema binário.

O que poderia mover-nos, então, para a vontade de abrir o sistema lógico no qual cotidianamente nos desenvolvemos? Basta olhar ao redor: discriminação, injustiça, desigualdade, destruição, exploração desenfreada dos recursos, mentalidade imediatista, entreguismo, conformismo, falta de solidariedade, Estado de bem estar e de mal estar, crenças sem fundamentos, dissolução da ética, cinismo, egoísmo do egoísta, egoísmo do altruísta, dogmatismo, relativismo, barbárie, barbárie do dogmatismo e barbárie do relativista. As misérias não acabam aqui. Seu catálogo, como se pode imaginar, é muito mais extenso.

Se a classificação mostra um só mundo e, portanto, realça o desconhecimento, a opção é elaborar estratégias desclassificatórias. Do mesmo modo que se desclassifica um arquivo ou a informação para fazê-la pública, devemos desclassificar e desvelar a complexidade do mundo para fazê-lo mais acessível ao entendimento. $E$ isso só pode se obter instalando, em nosso sistema de raciocínio, uma ferramenta metacognitiva - de autovigilância crítica baseada no pluralismo lógico, que não é mais que a convicção profunda do respeito ao outro - a única lógica digna -, seja contemporâneo, sucessor ou predecessor $^{15}$.

Evadir-nos da classificação, ou afastarmo-nos, mesmo que um passo, é tão utópico como querer fugir da linguagem ou do pensamento. Se logramos escapar de um sistema será porque, imediatamente, outro ocupará seu lugar. Isso ocorre porque uma condição do conhecimento é a classificação. Poderíamos conhecer com outras categorias, mas sempre mediante categorias. Essas outras categorias, que propomos em nosso projeto epistemográfico desclassificatório, haveriam de evitar o hermetismo, o estancamento, o dogmatismo e o relativismo, e dotar-se de configurações abertas, permeáveis, sensíveis, plurais.

Se como disse John Holloway, toda classificação do mundo toma como ponto de partida uma inflexível posição identitária, superemos voluntariamente nossa identidade e desclassifiquemos. $\mathrm{E}$, possivelmente, o "grito" de Munsch deva formar parte do coração desclassificador.

A Sociedade do Conhecimento, aquela a que devemos aspirar, há de ser uma sociedade desclassificada, isto é, heteroconstruída desde autonarrações múltiplas, a partir de estruturas e processos suficientemente flexíveis para incrementar, em seu interior, mais dissenso e configurações lógicas plurais. No mundo atual do pensamento e das tecnologias unificantes, sabemos que o consenso corre menos riscos do que o dissenso. Dissentir, então, mais do que consentir.

Por isso, uma das chaves da promoção dessa nova sociedade global, mais do que potencializar o diálogo para favorecer o consenso, consistiria justamente no contrario: em promover o dissenso - mediante a desclassificação - para aumentar o diálogo e, conseqüentemente, o conhecimento.

15 Inclusive, acredito menos no universalismo diacrónico que no universalismo sincrónico. 


\section{REFERÊNCIAS}

COSTA, N.C.A. Oconhecimento cientifico. São Paulo: Discurso Ed. 1997.

ELSTER, J. Ulises y las sirenas. Estudios sobre racionalidade irracionalidad. México: FCE, 1989. p.181.

GARCÍA GUTIÉRREZ, A. Principios de lenguaje epistemográfico: la representación del conocimiento sobre patrimonio histórico andaluz. Sevilla; Granada: Consejería de Cultura de la Junta de Andalucía, Instituto andaluz del Patrimonio histórico; Comares, 1998.

GARCÍA GUTIÉRREZ, A. La memoria subrogada: mediación, cultura y conciencia en la red digital. Granada: Editorial de la Universidad de Granada, 2002.

GARCÍA GUTIÉRREZ, A. Otra memoria es posible. Estrategias descolonizadoras del archivo mundial. Buenos Aires: La Crujía, 2004.

GARCÍA GUTIÉRREZ,A. Fijaciones. Estudios críticos de políticas, culturas y tecnologías de la memoria. Madrid: Biblioteca Nueva, 2005, Nuevas Eutopías.
GARCÍAGUTIÉRREZ, A. Dialéctica de la exomemoria. Temuco: Universidad de la Frontera, 2006. (en prensa).

GARDIN, J.C. et al. La logique du plausible. Éssais d'Epistémologie pratique en Sciences humaines. 2.ed. Paris: Maison des Sciences de l'Homme, 1987.

HARAWAY, D. Situated Knowledges: The Science Question in Feminism and the Privilege of Partial Perspective. "Feminist Studies", 1988.

HARDT, M.; NEGRI, A. Imperio. Barcelona: Paidós, 2002.

LATOUR, B.; WOOLGAR, S. La vida en el laboratorio: la construcción de los hechos científicos. Madrid: Alianza, 1995.

MARINA, J.A. La inteligencia fracasada. Barcelona: Anagrama, 2005. p.35.

PLATÓN, F. Diálogos III. Madrid: Gredos, 1997.

SANTOS, B.S. Introduçâo a uma ciência pósmoderna. Rio de Janeiro: Graal, 1989.

STEINER, G. Gramáticas de la creación. Madrid: Siruela, 1999. p.25-91 